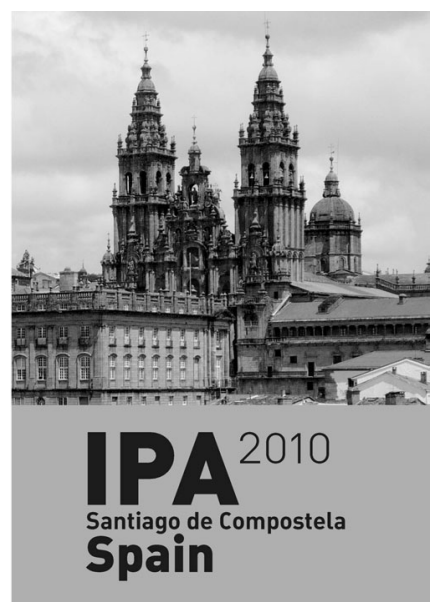

International Psychogeriatric Association

2010 International Meeting

26-29 September 2010

Santiago de Compostela, Spain

Diversity • Collaboration • Dignity

www.ipa-online.org

\title{
Pre-Meeting Programs
}

Friday, 24 September

Long-Term Care Symposium

Co-Chairs: Wendy Moyle, Australia

Arantza Pérez, Spain
Saturday, 25 September

Neuroimaging in Dementia Workshop

Co-Chairs: John T. O'Brien, United Kingdom

Leonardo Pantoni, Italy

\section{International Meeting Scientific Program}

\section{Plenary Sessions}

Opening Session/Raymond Levy Lecture

The 10/66 Dementia Research Group Studies of the prevalence, incidence, impact and aetiology of cognitive and mental disorders in Latin America, India and China - Martin Prince, United Kingdom

Psychosocial intervention (or person-centered care) to prevent and treat agitated behavior in persons with dementia - Jiska Cohen-Mansfield, Israel / United States

Depression in the elderly - How to prevent and treat a heterogeneous disorder - Jerson Laks, Brazil

\section{Symposia and Workshops}

- Introducing the IPA BPSD Educational Pack, 2010 Revision - Chair: Brian Draper, Australia

- Psychotherapy developments in depression and dementia - Chair: Ken Laidlaw, Scotland

- Addressing unresolved issues in geriatric depression - Chair: Luis Agüera Ortiz, Spain

- Memory clinics around the world - Chair: Ricardo Allegri, Argentina

- Early onset dementia: The need for special care - Chair: Raymond Koopmans, The Netherlands

- Mental health and social factors - Co-Chairs: Sabine Bährer-Kohler, Switzerland and Elaine T. Jurkowski, United States

- Physical and psychosocial environment: How can it support person-centered care? Chair: Helle Wijk, Sweden

- $\quad$ Shifting paradigm in old age psychiatry - Chair: Nicola Lautenschlager, Australia

- Psychogeriatrics in primary care - Chair: Carlos de Mendonça Lima, Portugal

- Alzheimer Europe, Alzheimer's Disease International and Alzheimer Spain - Challenges for carers of patients with dementia - Chair: Daisy Acosta, United Kingdom / Dominican Republic

- Sociedad Española de Psicogeriatria and Faculty of Old Age Psychiatry of the Royal College of Psychiatrists Symposium - Co-Chairs: Raimundo Mateos, Spain and Anand Ramakrishnan, United Kingdom

- Associaçao Portuguesa de Gerontopsiquiatria - Gerontopsychiatry Services in Portugal Co-Chairs: Duarte Falcão and Lia Fernandes

- Associaçao Portuguesa de Gerontopsiquiatria - Old Age Education and Research in Portugal Co-Chairs: Horácio Firmino and António Leuschner

- Bob Dylan's Musical Life Review: A Study in Creative Resilience \& Aging Chair: Jeffrey M. Lyness, United States

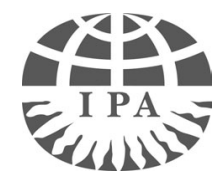




\title{
Save the Date!
}
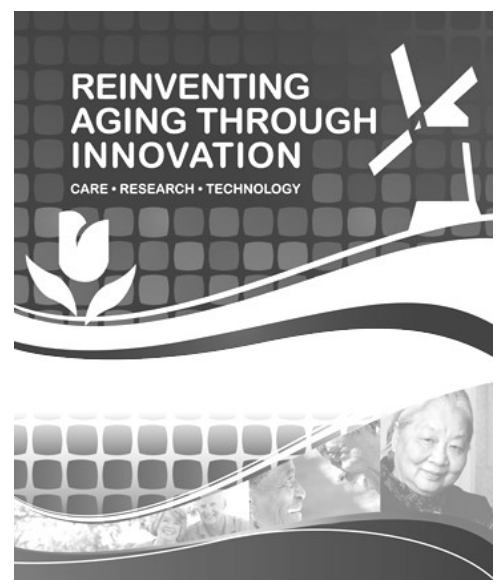

\section{$15^{\text {th }}$ International Congress Reinventing Aging Through Innovation Care • Research • Technology}

\author{
6-9 September 2011 \\ The Hague, The Netherlands
}

The International Psychogeriatric Association (IPA) is committed to bringing the newest information from the field to its scientific programs.

For information contact the IPA Secretariat:

Email: ipa@ipa-online.org Web: www.ipa-online.org

IPA ... Better Mental Health for Older People 


\section{Encourage a Colleague to Join}

The International Psychogeriatric Association (IPA) is the leading multidisciplinary, international organization dedicated to the advancement of geriatric mental health knowledge.

\section{Benefits of IPA Membership Include}

- An opportunity to interact with colleagues around the world who share an interest in advancing research, education, and theory about mental health in older people

- Education and meetings reflecting the many disciplines in Psychogeriatrics and the collective expertise of the world; IPA members receive special "members only" rates for all our meetings and activities

- A subscription to International Psychogeriatrics, IPA's peer-reviewed journal, which includes eight issues per year and any additional special-focus supplements

- The IPA Bulletin, an informative quarterly newsletter

- IPA Online - the IPA website - including member area with special features including access to fellow members, and the IPA Learning Portal

- Support the growth of Psychogeriatrics around the world, including contributing to the Sponsored Member Program to help associations in developing countries pass knowledge to their members

- Behavioral and Psychological Symptoms of Dementia (BPSD) Education Materials are available to IPA members in electronic format at no charge. The BPSD materials include the seven module BPSD Education Pack (revision currently in process), the Primary Care Physician's Guide to BPSD, and the Nurses' Guide to BPSD.

IPA's membership dues have been adjusted to accommodate the needs of a wide variety of colleagues worldwide. To find out what the membership rates are for your country, please visit www.ipa-online.org.

To join or to obtain a membership application, bookmark the IPA website at http://www.ipa-online.org, or contact:

International Psychogeriatric Association

E-mail: membership@ipa-online.org Website: http://www.ipa-online.org

Telephone: +1.847.501.3310 • Fax: +1.847.501.3317

550 Frontage Road, Suite 3759

Northfield, IL 60093 USA

\section{IPA ... Better Mental Health for Older People}




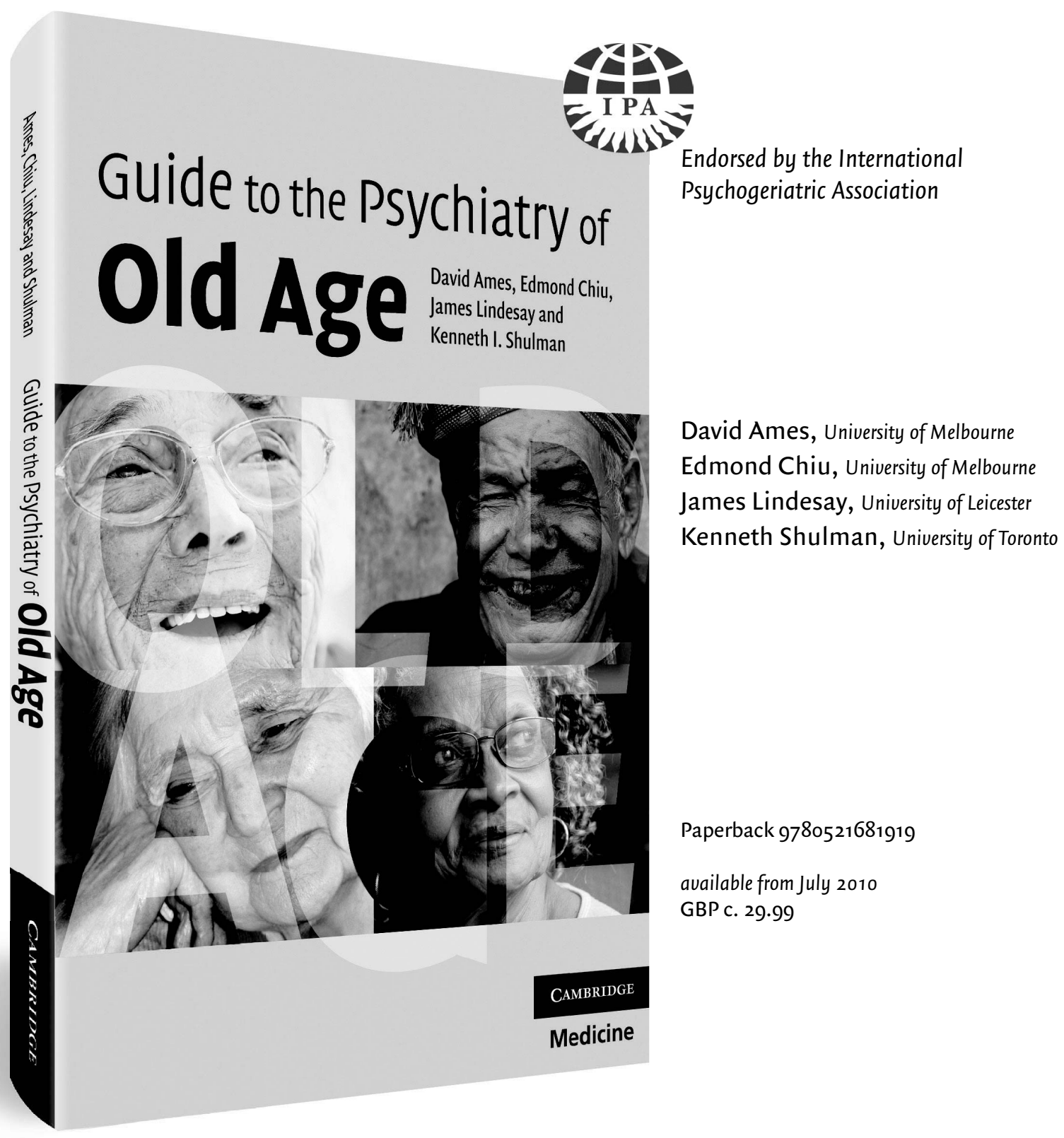

\section{Compact, accessible and affordable}

Each chapter is sharp, clear and practical, enhanced by tables and diagrams for quick assimilation and reference on the ward or in the clinic

Coverage also includes legal and ethical issues, and the neglected topic of alcohol and drug abuse in the elderly 


\section{Encourage a Colleague to Join}

The International Psychogeriatric Association (IPA) is the leading multidisciplinary, international organization dedicated to the advancement of geriatric mental health knowledge.

\section{Benefits of IPA Membership Include}

- An opportunity to interact with colleagues around the world who share an interest in advancing research, education, and theory about mental health in older people

- Education and meetings reflecting the many disciplines in Psychogeriatrics and the collective expertise of the world; IPA members receive special "members only" rates for all our meetings and activities

- A subscription to International Psychogeriatrics, IPA's peer-reviewed journal, which includes eight issues per year and any additional specialfocus supplements

- The IPA Bulletin, an informative quarterly newsletter

- IPA Online - the IPA website - including member area with special features including access to fellow members, and the IPA Learning Portal

- Support the growth of Psychogeriatrics around the world, including contributing to the Sponsored Member Program to help associations in developing countries pass knowledge to their members

IPA's membership dues have been adjusted to accommodate the needs of a wide variety of colleagues worldwide. To find out what the membership rates are for your country, please visit www.ipa-online.org.

To join or to obtain a membership application, bookmark the IPA website at http://www.ipa-online.org, or contact:

International Psychogeriatric Association

E-mail: membership@ipa-online.org Website: http://www.ipa-online.org

Telephone: +1.847.501.3310 • Fax: +1.847.501.3317

550 Frontage Road, Suite 3759

Northfield, IL 60093 USA

\section{IPA ... Better Mental Health for Older People}




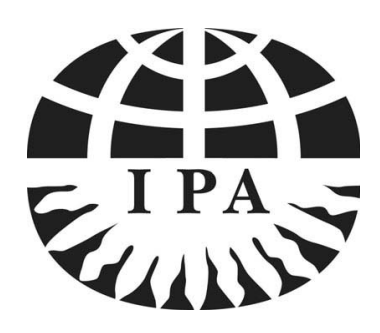

\title{
International Psychogeriatric Association (IPA)
}

Representing more than 66 countries around the world, IPA is a unique and diverse professional healthcare community promoting better geriatric mental health - across disciplines, across borders, and across geriatric issues. Psychiatrists, Scientists, Neurologists, Geriatricians, Primary Care Physicians, Epidemiologists, Nurses, Psychologists, Occupational Therapists, Social Workers, and many other healthcare professionals come to the IPA community from all over the globe to discuss, learn, share, and research information about behavioral and biological aspects of geriatric mental health. IPA's leaders and members contribute their wealth of expertise and knowledge from the research, clinical, education, service and program development arenas.

There are many benefits to being a member of IPA, including a subscription to this peer-reviewed journal, International Psychogeriatrics. For more information please contact info@ipa-online.org.

\section{IPA Board of Directors}

\author{
Officers \\ Masatoshi Takeda, President, Japan \\ Jacobo Mintzer, President-Elect, United States \\ Jill Rasmussen, Treasurer, United Kingdom \\ Horácio Firmino, Treasurer-Elect, Portugal \\ Daniel O'Connor, Secretary, Australia
}

Helen Fung-kum Chiu, Immediate Past President, Hong Kong SAR PR China

\section{Directors}

Ricardo F. Allegri, Argentina

Heii Arai, Japan

Sabine Bährer-Kohler, Switzerland

Olusegun Baiyewu, Nigeria

Susan Benbow, United Kingdom

Cássio Machado de Campos Bottino, Brazil

Ramón Cacabelos, Spain

David Conn, Canada

Peter Paul De Deyn, Belgium

Brian Draper, Australia

Serge Gauthier, Canada

Ken Laidlaw, United Kingdom

Carlos de Mendonça Lima, Brazil
Jay Luxenberg, United States

Kiyoshi Maeda, Japan

Raimundo Mateos, Spain

Pamela Melding, New Zealand

John T. O'Brien, United Kingdom

Nancy Pachana, Australia

Leonardo Pantoni, Italy

Anne Margriet Pot, Netherlands

John A. Snowdon, Australia

Guk-Hee Suh, South Korea

Gregory Swanwick, Ireland

Frans R.J. Verhey, Netherlands 


\section{International psyanogentatics

\section{Scope and contributions}

International Psychogeriatrics is written by and for those doing clinical, teaching, and research work with older people. It is the official journal of the International Psychogeriatric Association (IPA) and is published by Cambridge University Press, Cambridge, UK. Although it is primarily concerned with psychogeriatrics, the journal welcomes contributions from all concerned with the field of mental health and aging. Original research papers are particularly sought.

Contributions include original research articles, case reports, reviews of the literature, book reviews, letters to the editor, and editorials. Apart from editorials and book reviews, which are commissioned, contributions to International Psychogeriatrics are spontaneously written and submitted by authors. Papers are reviewed by two expert reviewers selected by the Editor-in-Chief. At present, about half of the papers submitted are accepted for publication. The journal's Science Citation Index Impact Factor (2008) is 2.098 . Submission of a paper implies that it is neither under consideration for publication elsewhere, nor previously published in English. Manuscripts must be formatted double-spaced with ample margins on all sides and the pages should be numbered. International Psychogeriatrics uses the spelling of American English. Manuscripts written by those whose primary language is not English should be edited carefully for language prior to submission. The journal has a Language Assistance Panel consisting of both native English speakers willing to check mauscripts for style prior to submission, and bilingual experts willing to assist with the translation of manuscripts into English. Further details including contact information for individual panel members can be found at both the journal and IPA websites (journals.cambridge.org/ipg and www.ipa-online.org).

An up to date version of the journals instructions for contributors can be found at the International Psychogeriatrics website journals. cambridge.org/ipg. Please read these instructions carefully before submitting articles. Articles that are not prepared in accordance with these guidelines will be returned to authors.

Manuscripts should be submitted online via our manuscript submission and tracking site, <http://mc.manuscriptcentral.com/ipg>. Full instructions for electronic submission are available directly from this site.

\section{Important Addresses}

Office of the Editor-in-Chief

Professor David Ames, Editor-in-Chief, International Psychogeriatrics

Normanby House,

St George's Hospital,

283 Cotham Rd.,

Kew, Victoria 3101 ,

Australia

Email:ipaj-ed@unimelb.edu.au

Tel +61398160485

Fax +61398160477
For business matters:

Ms. Susan M. Oster

Managing Editor, International Psychogeriatrics

International Psychogeriatric Association

550 Frontage Road,

Suite 3759

Northfield, IL 60093

USA

Email:ipa@ipa-online.org

Tel: +1 8475013310

Fax: +1 8475013317

Web: www.ipa-online.org

\section{For book review matters:}

Dr. Michael Philpot

Maudsley Hospital,

Mental Health of Older Adults Directorate

115 Denmark Hill,

London SE5 8AZ

U.K.

Email:

mike.philpot@slam.nhs.uk

Tel: +44(0)2032281640

Fax: +44 (0)2032281619.

This journal issue has been printed on FSC-certified paper and cover board. FSC is an independent, non-governmental, not-for-profit organization established to promote the responsible management of the world's forests. Please see www.fsc.org for information.

Enquiries about advertising should be sent to the Journal's Promotion Department of the Cambridge or American Branch of Cambridge University Press. 


\section{International Psychogeriatrics}

CONTENTS

Editorial 681 Recent developments at International Psychogeriatrics David Ames (Australia)

Reviews 683 Management of inappropriate sexual behaviors in dementia: a literature review Inese Tucker (Australia)

693 The mental health of older prisoners

Alexander Kakoullis, Nick Le Mesurier and Paul Kingston (U.K.)

702 Specific phobias in older adults: characteristics and differential diagnosis

Carlos M. Coelho, Daniela C. Gonçalves, Helena Purkis (Australia), Margarida Pocinho (Portugal), Nancy A. Pachana and Gerard J. Byrne (Australia)

712 Depressive morbidity and gender in community-dwelling Brazilian elderly: systematic review and meta-analysis Ricardo Barcelos-Ferreira, Rafael Izbicki (Brazil), David C. Steffens (U.S.A.) and Cássio M. C. Bottino (Brazil)

Original Research 727 A replication of the relationship between elderly suicide rates and the human development index in a cross-national study Articles Ajit Shah (U.K.)

733 Approach to major depression in old people Beatriz Navarro, Fernando Andrés, Ignacio Párraga, Susana Morena, José Miguel Latorre and Jesús López-Torres (Spain)

739 Mental distress and service utilization among help-seeking, community-dwelling older adults Adam Simning, Thomas M. Richardson, Bruce Friedman, Lisa L. Boyle, Carol Podgorski and Yeates Conwell (U.S.A.)

750 Perceptions of subjective memory complaint in older adults: the Illness Perception Questionnaire - Memory (IPQ-M) Catherine S. Hurt, Alistair Burns, Richard G. Brown and Christine Barrowclough (U.K.)

761 A five-year community-based longitudinal survival study of dementia in Beijing, China: a 10/66 Dementia Research Group population-based study Ying Wang, Yueqin Huang, Zhaorui Liu, Chuanjun Zhuo, Shuran Li (China) and Martin Prince (U.K.)

769 The process of family-centered counseling for caregivers of persons with dementia: barriers, facilitators and benefits Myrra Vernooii-Dassen, Karlijn Joling, Hein van Hout (The Netherlands) and Mary Sherman Mittelman (U.S.A.)

778 Living alone with dementia: lack of awareness adds to functional and cognitive vulnerabilities Susan W. Lehmann, Betty S. Black, Andrew Shore, Judith Kasper and Peter V. Rabins (U.S.A.)

785 A novel approach to assessing memory at the population level: vulnerability to semantic interference Beth E. Snitz, David A. Loewenstein, Chung-Chou H. Chang, Ching-Wen Lee, Joni Vander Bilt, Judith Saxton and Mary Ganguli (U.S.A.)

795 Validity of a short computerized assessment battery for moderate cognitive impairment and dementia Tzvi Dwolatzky, Luba Dimant (Israel), Ely S. Simon and Glen M. Doniger (U.S.A.)

804 Homocysteine is associated with hippocampal and white matter atrophy in older subjects with mild hypertension Michael J. Firbank, Sunil K. Narayan, Brian K Saxby, Gary A. Ford and John T. O'Brien (U.K.)

812 Rivastigmine in the treatment of delirium in older people: a pilot study Ross Overshott, Martin Vernon, Julie Morris and Alistair Burns (U.K.)

819 Apathy and cognitive and functional decline in community-dwelling older adults: results from the Baltimore ECA longitudinal study Diana E. Clarke (U.S.A./Canada), Jean Y. Ko, Constantine Lyketsos, George W. Rebok and William W. Eaton (U.S.A.)

Case Reports 830 Electroconvulsive therapy for treatment of late-onset obsessive compulsive disorder Samantha Loi and Richard Bonwick (Australia)

832 Primary arachnoid cyst mimicking depressive symptoms in an elderly woman Hester R. Boomkens, Tischa J. M. van der Cammen and Francesco U. S. Mattace-Raso (The Netherlands)

834 Manic episode precedes development of early dementia: a case report Li Yu Hu and Yuan-Hwa Chou (Taiwan)

837 New onset multimodal hallucinations associated with mirtazapine: a case report Kalpana P. Padala, Prasad R. Padala, Timothy Malloy and William J. Burke (U.S.A.)

840 The case of an aging person with borderline personality disorder and possible dementia

Letter Edward Helmes and Lynda Steward (Australia)

Book Reviews 846 